\title{
TRINTA DIAS EM UM HOSPITAL DE CUSTÓDIA E TRATAMENTO PSIQUIÁTRICO
}

\section{THIRTY DAYS IN A HOSPITAL FOR CUSTODY AND PSYCHIATRIC TREATMENT}

Fábio Franco $^{1}$

Fábio Franco. Trinta dias em um hospital de custódia e tratamento psiquiátrico. Rev Bras Crescimento Desenvolv Hum. 2010; 20(1): 90-94

\section{Resumo:}

A partir do relato de casos atendidos no Hospital de Custódia e Tratamento Psiquiátrico 'André Teixeira Lima' de Franco da Rocha, apresenta-se algumas reflexões no âmbito da ‘saúde mental e justiça'. Trataremos das condições sociais e psíquicas que possibilitam, dificultam ou mesmo impedem o processo de subjetivação necessário ao exercício da ética. Será focalizado o tema da neutralidade e seu papel no atendimento de pacientes que sofreram falhas em seu processo de subjetivação. Para tanto, serão utilizados conceitos psicanalíticos e, em especial, uma definição de ética que se articula com a técnica em psicanálise.

Palavras-chave: psicoanálise; ética; psiquiatria comunitária; psiquiatria.

\begin{abstract}
:
After we report cases treated at the Custody Hospital and Psychiatric Treatment 'André Teixeira Lima' de Franco da Rocha, we present some debate on 'mental health and justice'. We deal with social and psychological conditions which enable, inhibit or even block the process of subjectivity necessary to the exercise of ethics. It is focused the issue of neutrality and its role in caring for patients who have suffered failures in the process of subjectivity. For this, we used psychoanalytic concepts and, in particular, a definition of ethics that articulates with the technique in psychoanalysis.
\end{abstract}

Key words: psychoanalysis; ethics; community psychiatry; psychiatry.

Apresentação oral realizada no I Simpósio Internacional sobre Manicômios judiciários e Saúde Mental ocorrido em setembro de 2009 na Faculdade de Saúde Pública da USP.

1 Fábio Franco é psicólogo, especialista em psicologia clínica: teoria psicanalítica pela PUC-SP e mestrando em psicologia clínica pela PUC-SP. Trabalha no Hospital de custódia e tratamento psiquiátrico 'Prof. André Teixeira Lima', leciona na Universidade Nove de Julho e atende em consultório particular.

Correspondência para: Fábio Franco - Rua Cardoso de Almeida, 1005 - casa 3 - CEP 05013-001 - Perdizes - São Paulo - SP Tel. (11) 38737817 - Email: fabiofranco@uninove.br 


\section{INTRODUÇÃO}

Os pacientes psicóticos do Manicômio Judiciário devem ser tratados integralmente. Assim, quais seriam as melhores formas de atendê-los? Arte terapia? Psicoterapia de grupo? Acompanhamento terapêutico?

\section{Aconselhamento psicológico ou Psicoterapia individual?}

Hoje reconheço que não existe uma técnica mais eficiente para tratar os pacientes do Manicômio Judiciário. O mais importante é a adoção de uma postura ética junto aos pacientes. Percebi com os atendimentos que a grande maioria dos pacientes teve pais ausentes, agressivos, falecidos e/ou usuários de substâncias entorpecentes, ou seja, não apresentavam uma postura ética face ao cuidar, pois estavam impossibilitados de reconhecer aquelas crianças como sujeitos singulares, únicos. Quero ilustrar estas impressões inicialmente através da apresentação de três casos.

\section{Três casos clínicos}

O Sr. A iniciou a entrevista informando que esteve pela primeira vez no hospital de custódia por ter matado o seu pai. Disse que seu pai abusava sexualmente das irmãs e batia muito na sua mãe. Durante a infância (mais ou menos cinco anos) o pai tentou abusar também dele.

Devido aos constantes abusos as irmãs do Sr. A saíram de casa muito cedo. Uma fugiu e a outra se casou aos quatorze anos. O Sr. A disse que quando suas irmãs eram crianças seu pai colocava uma delas em cada perna e lhes mostrava revistas pornográficas. O Sr. A disse ainda que era comum seu pai praticar sexo com animais. Cachorros e galinhas eram os mais comuns.

Após tornar-se adulto, aos vinte e um anos de idade ele estava tomando banho e lembrou que a mãe havia dito que quando ele tinha sete meses de idade o pai dormiu na mesma cama que ele. Pensou o Sr. A: "se ele tentou abusar de mim quando eu tinha cinco anos imagine aos sete meses". O Sr. A disse que foi até a cozinha e procurou facas, mas como a mãe sabia que ele estava com a intenção de matar o pai, ela havia escondido todas as facas da casa. O Sr. A encontrou uma tesoura em umas das gavetas da cozinha, pegou-a e proferiu seis golpes com a tesoura no pescoço do pai e o matou. A polícia prendeu-o pela primeira vez e ele foi encaminhado ao HCTP I.

Após cumprir três anos de medida de segurança, o Sr. A foi posto em liberdade e voltou a morar na casa da mãe. As pessoas da vizinhança passaram a temê-lo. Após alguns meses ocorreu uma chacina próximo à sua casa e ele foi responsabilizado pelo ocorrido.

O Sr. A afirmava que não havia matado ninguém a não ser seu pai e atribuía a autoria da acusação a uma senhora que havia ficado com medo dele. Esta mulher era amante de seu tio, irmão de seu pai. O Sr. A disse que certa vez ameaçou atear fogo na casa dela e matar o tio, pois julgava que eles eram trapaceiros.

Às lágrimas, o Sr. A dizia que não queria ser julgado pelas pessoas. Dizia que o que havia sido feito não era mais possível desfazer e que teria que "carregar aquela cruz" pelo o resto de sua vida.

O paciente B tinha fama de ser agressivo apesar de ter me dito que sempre possível ele evitava confusão. B me disse que morava no interior, local onde trabalhava com o plantio e colheita de café e como domador de animais. Contou-me que certa vez vendeu algumas cabeças de gado para um homem que não lhe pagou a terceira parcela do valor combinado. Após algumas cobranças o referido homem suspeitou que B queria matá-lo passou a querer matar B antes disso. B antecipou-se e assassinou o homem com uma faca de açougueiro.

B foi preso e, na penitenciária, durante uma briga com outro preso, desferiu duas pauladas na cabeça dele. Os outros presos o seguraram e impediram que ele matasse o homem. 
O preso agredido ficou com seqüelas da agressão e não mais pode andar e, segundo $B$, ficou com algumas lesões cerebrais que dificultavam o pensamento e a fala.

B tinha apenas uma avó e sua ex-esposa, mãe de seus cinco filhos, passou a traí-lo após a sua prisão. B não tinha contato com nenhum familiar já há muitos anos.

O paciente disse que sua mãe morreu quando ele ainda era uma criança. Contou-me que seu pai era muito agressivo e mau. Certa vez, quando contava com nove meses de idade, seu pai, como de costume, chegou alcoolizado em casa e foi agredir sua mãe. Esta pegou o pequeno B e utilizou-o como escudo para evitar a agressão. Seu pai afastou-o e matou a sua mãe na sua frente a facadas e, depois, ateou fogo nela.

A partir daí B foi criado pelos avós, mas disse que sempre foi um homem agressivo. Seu avô faleceu e, na época da entrevista, tinha apenas esta avó que ele não via há muito tempo.

C já havia sido preso várias vezes e passado por várias unidades prisionais. O maior período de tempo que ele passara fora da cadeia foi oito anos, sendo que na época da entrevista ele contava sessenta e oito anos.

Disse que sofre muito desde criança. C contou-me que depois que nasceu sua mãe o abandonou na maternidade e ele cresceu no orfanato anexo a esta. Ele me contou que sua mãe não tinha condições de cuidar dele.

Após sete anos sua mãe foi buscá-lo no orfanato. Ao chegar a casa ele foi recebido com muito desprezo pelo pai. Três dias depois de ter chegado a sua nova casa, quando sua mãe ausentou-se por algumas horas, seu pai aproximou-se, deu-lhe um tapa na cara e disse: "vá embora daqui, seu diabinho. Esta casa não é sua!”. C decidiu que deveria ser engraxate para poder manter-se, mas após alguns dias de trabalho começou a roubar.

Desde muito pequeno o paciente começou a apanhar do pai. Disse que possuía várias mar- cas causadas por essas agressões espalhadas pelo corpo e mostrou-me uma cicatriz na cabeça.

C fugiu de casa e foi morar no Rio de Janeiro. Lá praticou alguns delitos, mas logo foi preso. Como era menor, foi encaminhado de volta à sua casa. Lá chegando, assim que a polícia saiu, ele disse que foi espancado pelo pai como nunca havia sido antes.

O paciente cresceu e foi trabalhar em uma fábrica que ficava próxima a linha férrea. Certo dia acabou se desentendendo com um dos funcionários e ambos acabaram discutindo. Um dia ele encontrou o homem andando na linha férrea e os dois começaram a lutar. O homem caiu no chão e C pegou uma pequena parte de trilho de trem solta na linha férrea e atirou na cabeça do homem. Com o impacto a caixa craniana se abriu e C pegou uma parte da massa encefálica do homem com as mãos e comeu-a.

Após o ocorrido $\mathrm{C}$ afastou-se do local e ninguém soube quem havia matado o homem. Outra pessoa foi acusada e presa pelo crime. C ficou culpado e entregou-se à polícia. No momento em que $\mathrm{C}$ entregou-se à polícia, o delegado não acreditou em suas palavras. Ele apenas passou a tomar o fato como verdadeiro quando viu marcas de sangue na calça de $C$.

C não era casado e não tinha filhos. Disse que nunca havia se interessado por mulheres, mas sim por homens. Disse ainda que seus pais já morreram e que ele ainda possui três de seus onze irmãos, mas há muitos anos não os via, sendo este o seu maior desejo: encontrar os irmãos.

\section{Ética e técnica}

Por que vivências como estas em que os indivíduos foram violentados durante sua chegada ao mundo eram tão comuns no manicômio judiciário? De que modo estas experiências que se caracterizam principalmente pela violência (sexual, física, psíquica) e pelo abandono haviam contribuído para que no futuro aqueles indivíduos cometessem atos que os levariam a uma situação de exclusão que não tinha data certa para terminar? Penso que luz 
pode ser lançada nesta questão se identificarmos os sentidos que possui o termo “ética”.

De acordo com Figueiredo ${ }^{1,2}$, existem várias formas de entender o termo ética, mas quando falamos de "ética” como substantivo estamos fazendo menção aos padrões e/ou códigos que permitem ou proíbem determinadas condutas. Assim, como os padrões e códigos variam de tempos em tempos, podemos afirmar que as éticas tanto indicam as diferenças nos modos de subjetivação quanto participam da constituição das subjetividades. Ou seja, as éticas tornam os indivíduos sujeitos morais inseridos em uma cultura historicamente determinada.

Etimologicamente ética deriva de ethos, que tanto pode significar hábitos e costumes como morada. Deste modo, considerar o ethos como casa, instalação, morada, implica reconhecer que ethos é, também, um local de aconchego, de acolhimento, onde podemos nos sentir a vontade. Apenas quando existe um espaço aconchegante para morar é possível despertar no corpo a capacidade para pensar e trabalhar. ${ }^{1,2,3}$

Daí, podemos chegar à premissa de que a criança quando vem ao mundo precisa ser acolhida em uma morada que lhe ofereça aconchego o que possibilita que os hábitos e costumes, padrões e códigos que proíbem ou permitem determinadas condutas sejam aprendidos. Ou seja, uma relação baseada na ética permite que ocorram trocas reguladas de afetos entre os indivíduos. É esta forma de relação que possibilita o desenvolvimento da confiança.

Safra $^{4}$ ensina que para que o ethos humano seja estabelecido, o homem tem a necessidade fundamental de ser recebido pelo outro. Se essa recepção for problemática, ou seja, se a criança sofrer abusos como violência psíquica, corporal e/ou sexual ocorrerão variações de organização de personalidade, de acordo com o tipo de violência sofrido. Todos esses tipos de variação da organização da personalidade consistem em modos defensivos que os indivíduos encontraram para lidar com a violação da ética em que foram colocados.
Mas de que modo esta explicação poderia nos auxiliar a pensar o melhor modo de tratar os pacientes do manicômio judiciário de Franco da Rocha? Entendo que é através do estabelecimento do lugar da neutralidade. Pois, sustentar a neutralidade frente aos pacientes está ligado à ética das relações.

Laplanche $^{3}$ ensina que a neutralidade é "uma das qualidades que definem a atitude do analista no tratamento. $\mathrm{O}$ analista deve ser neutro quanto aos valores religiosos, morais e sociais, isto é, não dirigir o tratamento em função de um ideal (...)”. Ou seja, a adoção de uma postura neutra comporta uma disposição para aceitar o que o paciente traz sem predileção. Tal posição pode ser alcançada através da suspensão da instância moral.

Quando o profissional consegue adotar tal posição, ocorre o acolhimento da singularidade do indivíduo. Isto é a ética das relações! Reconhecer e aceitar o outro em sua singularidade.

É esta postura que favorece o processo de subjetivação do sujeito. Na medida em que reconhecemos e aceitamos o sujeito em sua singularidade, possibilitamos que ele constitua o seu si-mesmo, ou seja, que ele se aproprie de seu corpo e o tome como a morada de seu $e u$. Desta forma, as organizações do espaço e do tempo se tornam possíveis.

Algumas semanas após entrevistar o paciente B ele realizou uma saída terapêutica do Hospital que consistiu em um passeio pelo centro de Franco da Rocha, acompanhado por um agente de segurança.

Após o seu retorno, convidei B para conversarmos a respeito da sua saída. Na medida em que ele foi me contando o que havia feito durante a saída terapêutica, eu fui identificando as emoções ligadas à experiência e devolvendo para B através da fala. Ou seja, procurei refletir para B o que ele mesmo estava sentindo. Aquele paciente sentiu-se tão acolhido e compreendido que a partir daí estabelecemos uma relação de confiança muito importante para o avanço do tratamento. Na tarde seguin- 
te ele me procurou para que continuássemos o processo: ele havia me trazido fotos.

É nessa medida que Figueiredo ${ }^{2}$ ensina que as técnicas utilizadas para tratar podem e devem variar enquanto uma ética deve ser mantida em todas as práticas realizadas. Desta forma, enten-

\section{REFERÊNCIAS}

1. Figueiredo, L. C. Revisitando as psicologias: Da epistemologia à Ética nas práticas e discursos psicológicos São Paulo: EDUC; Petropolis: Vozes, 1995.

2. Figueiredo, L. C. e Coelho Junior, N. Ética e técnica em psicanálise - São Paulo: Escuta, 2000. do que é a adoção de uma postura ética no contato com os pacientes que consiste grande parte do cuidar. Somente desta forma podemos favorecer a constituição do outro enquanto sujeito ético, assim como reparar as falhas no processo de subjetivação que ocorreram no passado.

3. Laplanche, J. e Pontalis J.B. Vocabulário da psicanálise - São Paulo: Martins Fontes, 1992.

4. Safra, G. A Poética na clínica contemporânea - Aparecida: Idéias e Letras, 2004.

Recebido em 22 de agosto de 2009. Modificado em 02 de janeiro de 2010. Aceito em 30 de janeiro de 2010. 